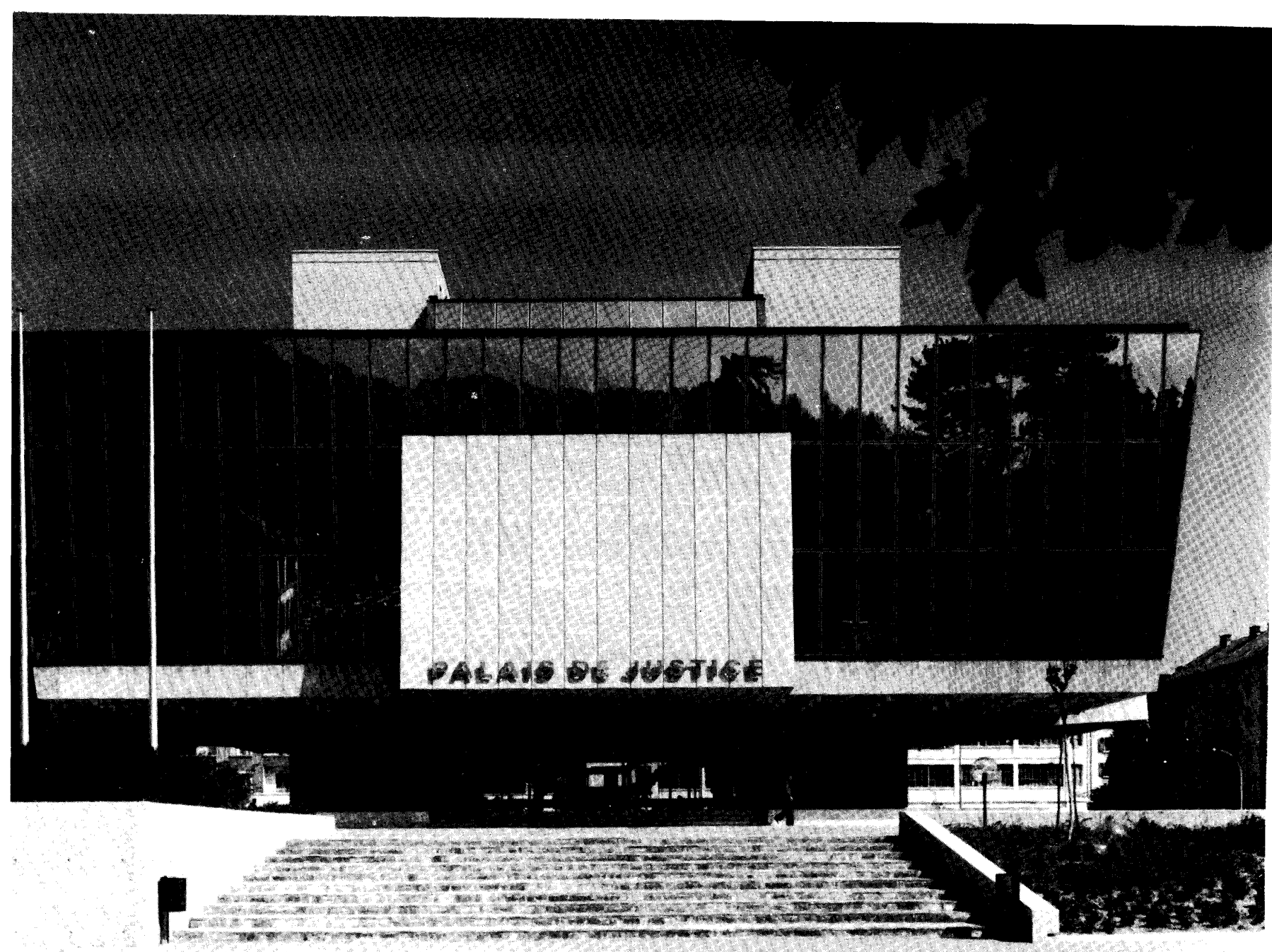

\title{
El Palacio de Justicia de Annecy - Francia
}

Maurice Novarina, Arquitecto

$145-105$

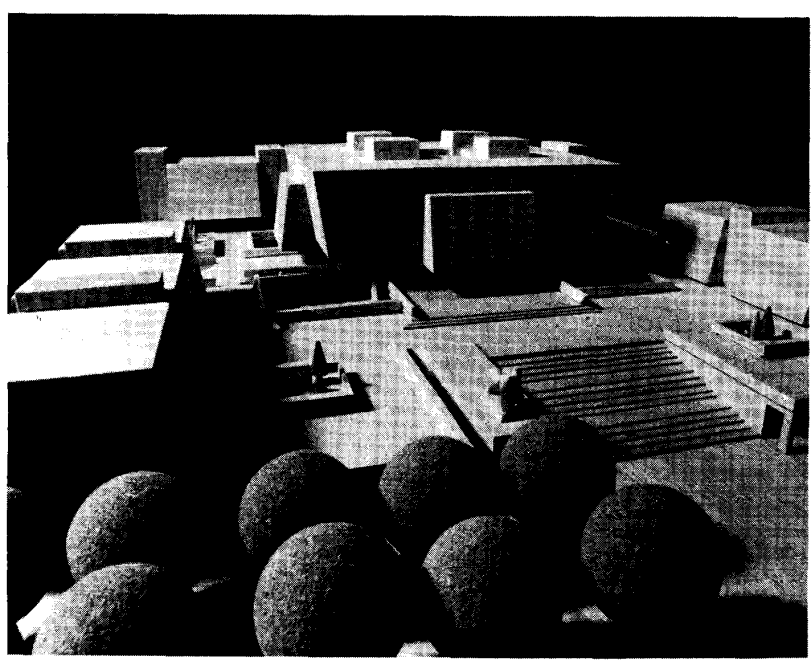

\section{sinopsis}

El Palacio de Justicia de Annecy, con forma de tronco de pirámide invertida, ocupa una superficie rectangular de unos $10.000 \mathrm{~m}^{2}$ en el centro de la ciudad.

Consta de una parte subterránea con dos sótanos y de un cuerpo alto sobre el nivel del terreno con planta baja y cuatro niveles superiores.

Se sustenta en cuatro pilares apoyados sobre una losa pavimentada. Las comunicaciones verticales están situadas en dichos pilares.

La fachada es, en su mayor parte, de aluminio con doble acristalamiento reflectivo. 


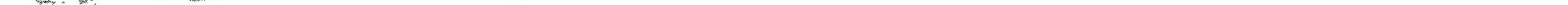



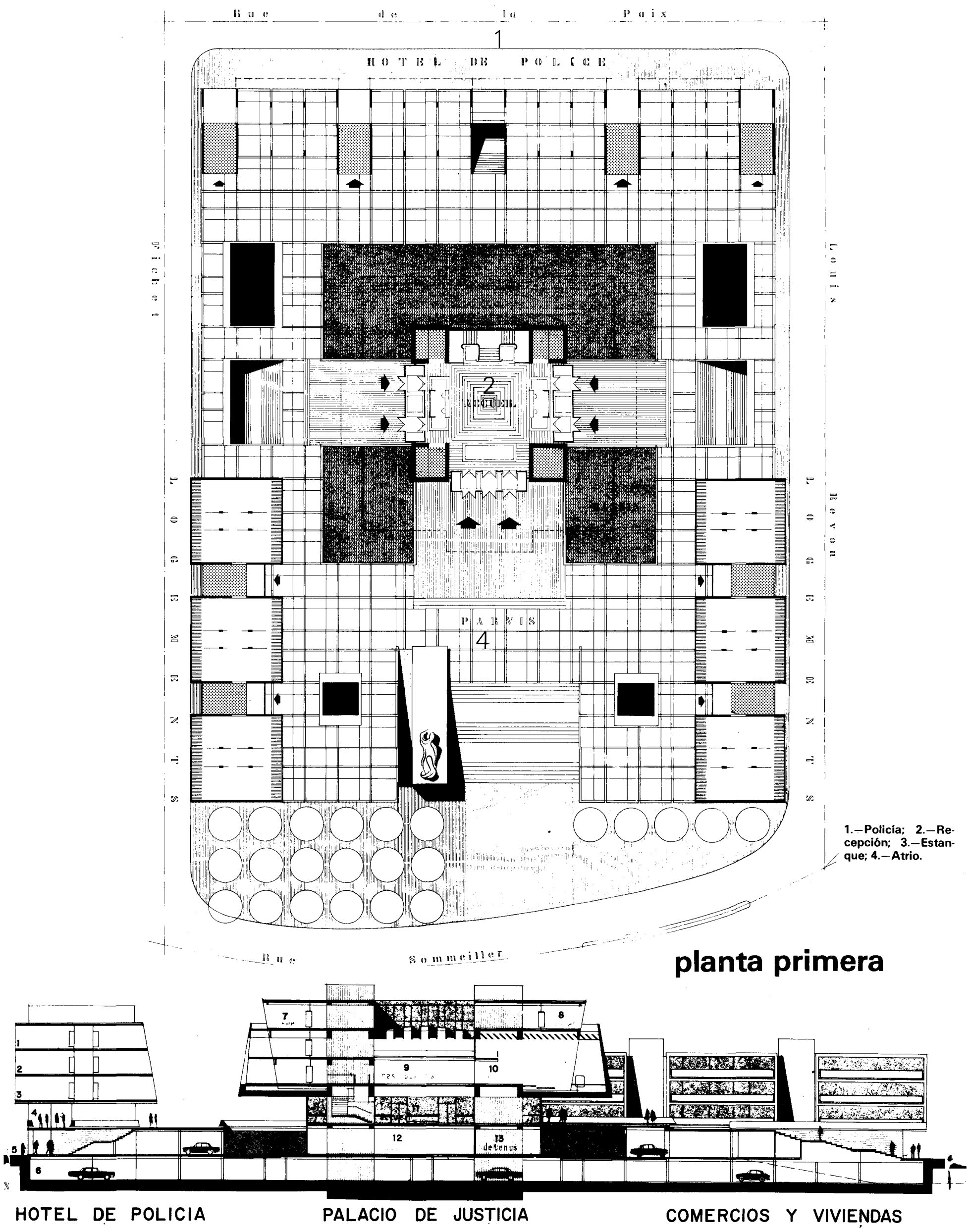

1.-Procurador y Presidente; 2.-Oficinas: 3.-Salas de audiencia 4--Recepción; 5.-Nivel calle: 6. - Aparcamiento; 7.-Sitiales; 8.-Tribunal; 9.-Pasos perdidos; 10.-Asientos; 11.-Recepción; 12.-Archi vos; 13.-Detenidos.

\section{sección longitudinal}



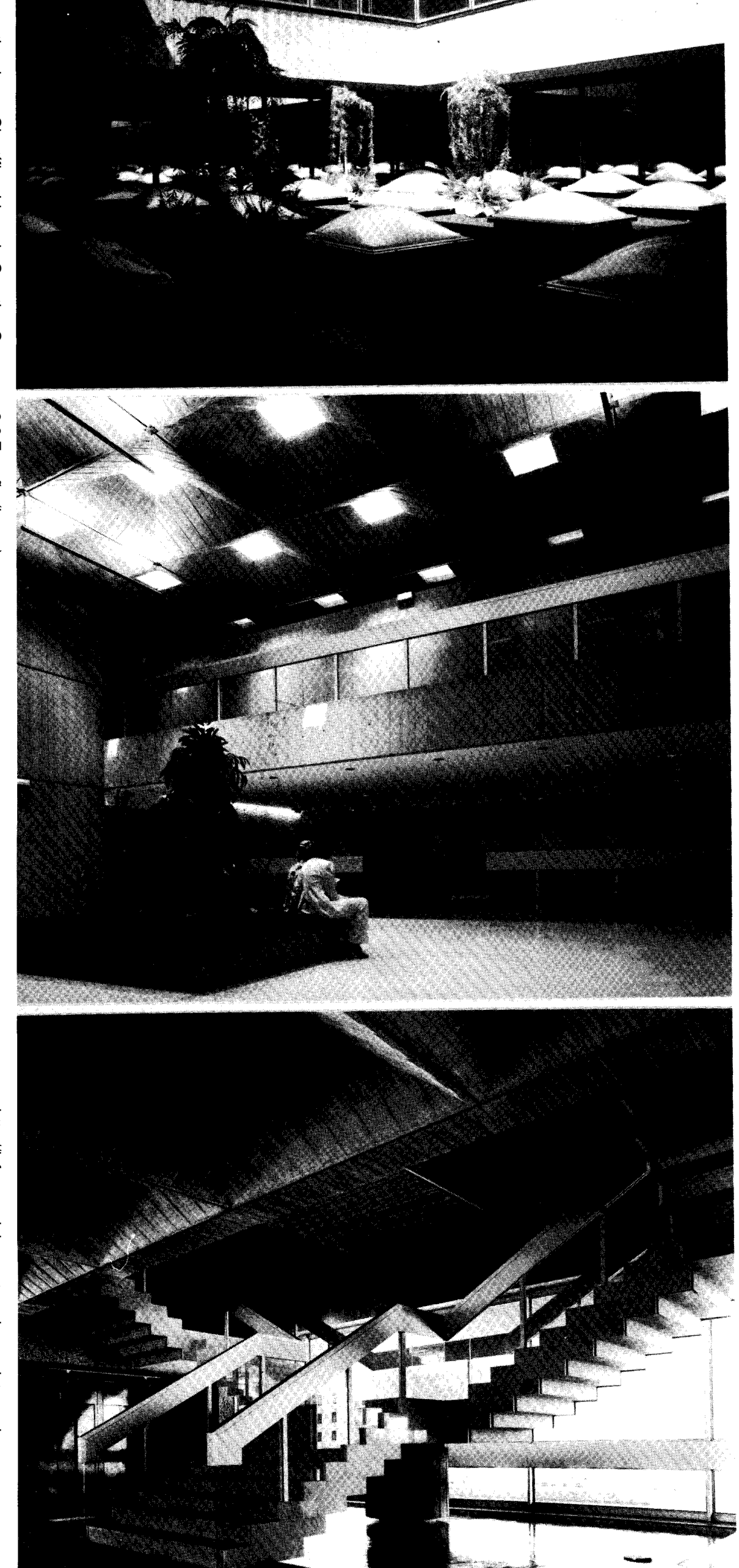


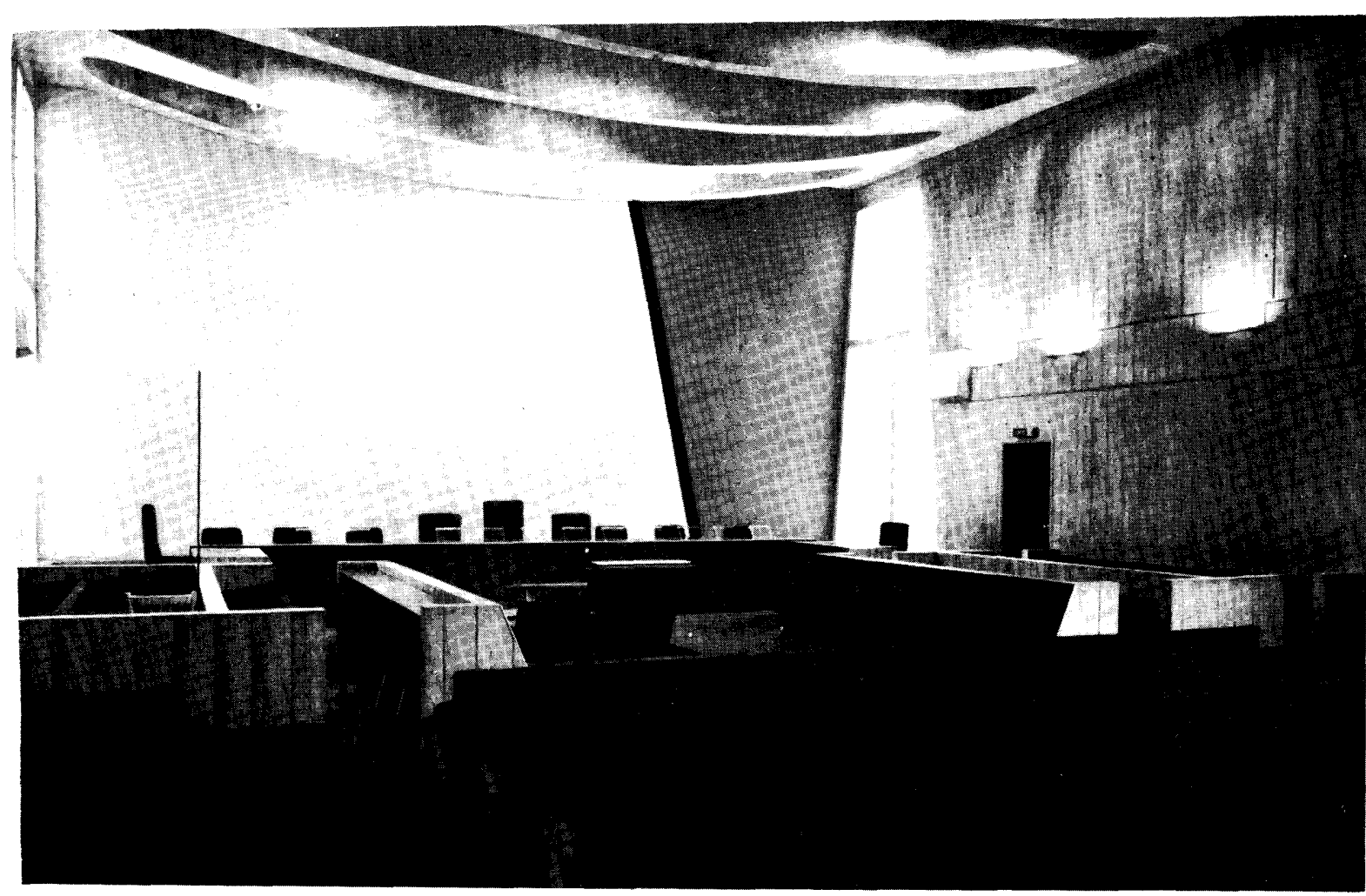

Fotos:

NNE HUBERT

y JEAN BIAUGEAUD.

\section{résumé}

\section{LE PALAIS DE JUSTIVE D'ANNECY .} FRANCE

Maurice Novarina, architecte

Le Palais de Justice d'Annecy, dont la forme est celle d'un tronc de pyramide inversé, occupe un terrain rectangulaire d'une superficie de $10.000 \mathrm{~m}^{2}$ au coeur du centre ville.

Il comprend un sous-sol, un rez-de-chaussée et quatre niveaux.

Ce bâtiment est supporté par quatre piliers reposant sur une dalle pavée. Les circulations verticales sot incluses dans ces piliers.

Il a une façade rideau en aluminium avec remplissage en double vitrage réfléchissant.

\section{summary}

COURTHOUSE AT ANNECY - FRAN-

CE

Maurice Novarima, architect

Annecy's Courthouse, shaped like an inverted truncated pyramid, occupies an area of some $10,000 \mathrm{~m}^{2}$ in the centre of the city.

The building has a below-grade part with two basements and an above-grade part with a ground floor and four upper storeys.

The building is supported on four box columns resting on a paved slab. Vertical traffic cores run inside these piers.

Most of the facade area is treated is aluminium supporting a reflectant double glacing.

\section{zusammenfassung}

JUSTIZPALAST IN ANNECY-FRANK-

\section{REICH}

Maurice Novarina, architekt

Der Justizpalast in Annecy hat die Form eines umgekehrten Pyramidenstammes und nimm eine rechteckige Fläche von etwa $10.000 \mathrm{~m}^{2}$ im Stadtzentrum ein.

$\mathrm{Er}$ besteht aus einem unterirdischen Teil mit zwei Kellergeschossen und einem überirdischen Körper mit Erdgeschoss und vier weiteren Stockwerken.

Vier auf einer gepflasterten Fliese abgestützte Pfeiler halten das Gebäude. Die Vertikalverbindungen wurden in diesen Pfeilern untergebracht

Die Fassade besteht zum grössten Teil aus Aluminium mit reflektierender Doppelverglas ung.

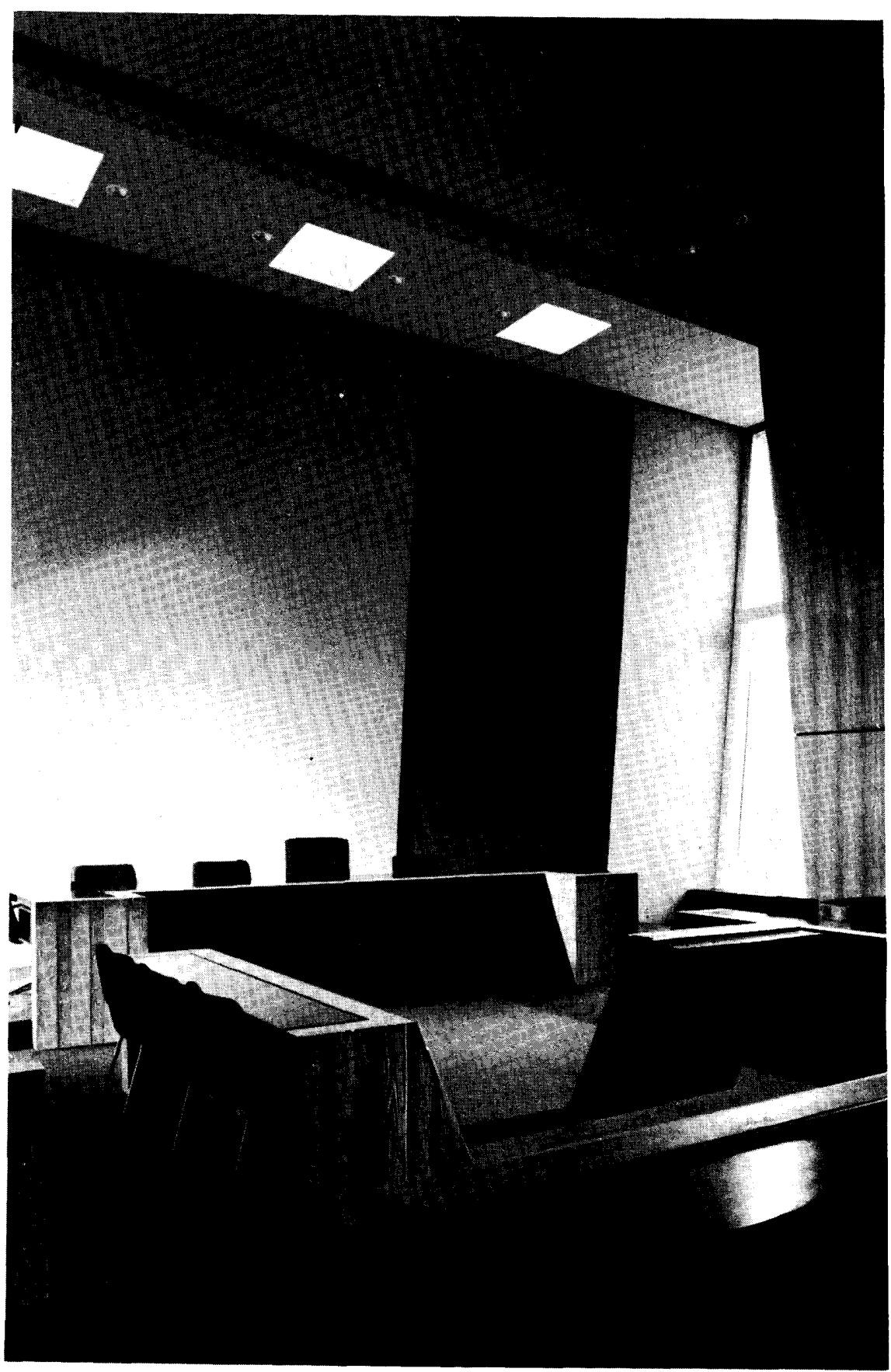

